\title{
Inhibition of NF-kB Activation and Cytokines Production in THP-1 Monocytes by 2-Styrylchromones
}

\author{
Ana Gomes ${ }^{1}$, João P. Capela ${ }^{2,3}$, Daniela Ribeiro ${ }^{1}$, Marisa Freitas ${ }^{1}$, Artur M.S. Silva ${ }^{4}$, \\ Diana C.G.A. Pinto ${ }^{4}$, Clementina M.M. Santos ${ }^{4,5}$, José A.S. Cavaleiro ${ }^{4}$, José L.F.C. Lima ${ }^{1}$ \\ and Eduarda Fernandes ${ }^{1 *}$
}

\begin{abstract}
${ }^{I}$ UCIBIO-REQUIMTE, Departamento de Ciências Químicas, Faculdade de Farmácia, Universidade do Porto, Rua Jorge Viterbo Ferreira $n^{\circ}$ 228, 4050-313 Porto, Portugal; ${ }^{2}$ UCIBIO-REQUIMTE, Departamento de Ciências Biológicas, Faculdade de Farmácia, Universidade do Porto, Rua Jorge Viterbo Ferreira $n^{\circ}$ 228, 4050-313 Porto, Portugal; ${ }^{3} F P-E N A S$ (Unidade de Investigação UFP em Energia, Ambiente e Saúde), CEBIMED (Centro de Estudos em Biomedicina), Faculdade, Portugal; ${ }^{4}$ Departamento de Química \& QOPNA, Universidade de Aveiro, 3810-193 Aveiro, Portugal; ${ }^{5}$ Departmento de Produção e Tecnologia Vegetal, Escola Superior Agrária de Bragança, Campus de Santa Apolónia, 5301-855 Bragança, Portugal
\end{abstract}

\begin{abstract}
Nuclear factor kappa B (NF-kB) is one of the most important transcription factors whose modulation triggers a cascade of signaling events, some of which are potential key targets for intervention in the treatment of inflammatory conditions. In addition, NF-kB activation has been linked to the carcinogenesis process because of its role in differentia-
\end{abstract}

Abstract: Nuclear factor kappa B (NF-kB) is one of the most important transcription factors whose modulation triggers a cascade of signaling events, namely the expression of many cytokines, enzymes, chemokines, and adhesion molecules, some of which being potential key targets for intervention in the treatment of inflammatory conditions. The 2-styrylchromones (2-SC) designation represents a well-recognized group of natural and synthetic chromones, vinylogues of flavones (2-phenylchromones). Several 2-SC were recently tested for their anti-inflammatory potential, regarding the arachidonic acid metabolic cascade, showing some motivating results. In addition, several flavones with structural similarities to 2-SC have shown NF-kB inhibitory properties. Hence, the aim of the present work was to continue the investigation on the interference of 2-SC in inflammatory pathways. Herein we report their effects on lipopolysaccharide (LPS)-induced NF-kB activation and consequent production of proinflammatory cytokines/chemokine, using a human monocytic cell line (THP-1). From the twelve 2-SC tested, three of them were able to significantly inhibit the NF-kB activation and to reduce the production of the proinflammatory cytokines/chemokine. The compound 3',4',5-trihydroxy-2styrylchromone stood up as the most active in both assays, being a promising candidate for an anti-inflammatory drug.

Keywords: Inflammation, Nuclear factor-kB, Pro-inflammatory cytokines, Styrylchromones, THP-1 monocytes.

\section{INTRODUCTION} tion, inflammation and cell growth [1].

In resting cells, NF-kB, which is composed mainly of two proteins, $\mathrm{p} 50$ and $\mathrm{p} 65$, is present within the cytoplasm in an inactive state, bound to its inhibitory protein, IкB. However, a number of proinflammatory stimuli [cytokines such as tumour necrosis factor (TNF)- $\alpha$ or interleukin (IL)-1, oxidative stress, infectious agents] can activate NF-kB in different cell types. These inflammatory stimulations can initiate an intracellular signaling cascade leading to $\mathrm{I} \kappa \mathrm{B} \alpha$ phosphorylation, by IкB kinase (IKK) complex, with its subsequent dissociation from NF-kB and degradation by the

\footnotetext{
*Address correspondence to this author at the UCIBIO-REQUIMTE, Departamento de Ciências Químicas, Faculdade de Farmácia, Universidade do Porto, Rua Jorge Viterbo Ferreira ${ }^{\circ}$ 228, 4050-313 Porto, Portugal; Tel: 00351220428675; Fax: 00351226093483; E-mail: egracas@ff.up.pt
}

proteasome. Once liberated from its inhibitory protein, NF$\mathrm{kB}$ translocates to the nucleus, where it orchestrates the transcription of a number of proinflammatory genes by binding to $\kappa \mathrm{B}$ motifs found in the promoter or enhancer region. This activates the expression of many mediators of the inflammation including, cytokines, enzymes, chemokines, and adhesion molecules [2].

Lipopolysaccharide (LPS) is a surface component of gram-negative bacteria released upon host infection. Its interaction with Toll-like receptor 4 (TLR4), located in cell membrane, initiates a signal transduction pathway, which leads, among other events, to the activation of NF-kB [3]. In monocytes, LPS-dependent activation of NF-kB complexes induces a rapid but transient expression of a defined set of genes including TNF- $\alpha$, IL-1 $\beta$, IL-6 and IL-8 [4]. These proinflammatory mediators have shown to play important roles in the pathogenesis of chronic inflammatory and autoimmune diseases such as rheumatoid arthritis, inflammatory bowel disease, or multiple sclerosis [5-8].

The 2-styrylchromones (2-SC) designation represents a well recognized group of natural and synthetic chromones, vinylogues of flavones (2-phenylchromones). As it occurs for flavones, several studies performed with 2-SC have dis- 
closed interesting activities with potential therapeutic applications, namely, neuroprotective action [9] and possible use in the treatment of cancers [5-8, 10-13], allergies [14], viral infections [15-17], gout [18] and oxidative stress related damage [19]. In fact the antioxidant properties of 2-SC have been shown in cellular [19] and non-cellular systems [20, $21]$. In a recent study, performed by our group, a number of 2-SC were shown to have anti-inflammatory potential by inhibiting both the production of leukotriene $\mathrm{B}_{4}$ in human neutrophils and the activity of the enzyme cyclooxygenase (COX)-1 in a non-cellular system [22]. Those promising results lead us to continue the investigation on the interference of 2-SC (Fig. 1) in inflammatory pathways. Herein we report their effects on LPS-induced NF-kB activation and production of TNF- $\alpha$, IL- $1 \beta$, IL- 6 and IL- 8 due to the above mentioned relevance of the NF-kB pathway in the inflammatory process and also to the fact that several flavonoids with structural similarities to 2-SC have shown interesting results in this field (see [23, 24] for reviews). The present studies were performed with the human monocytic leukemia cell line (THP-1). These cells were chosen because they display many characteristics similar to human monocytes and have been used previously to study the inflammatory process $[4$, 25-28].

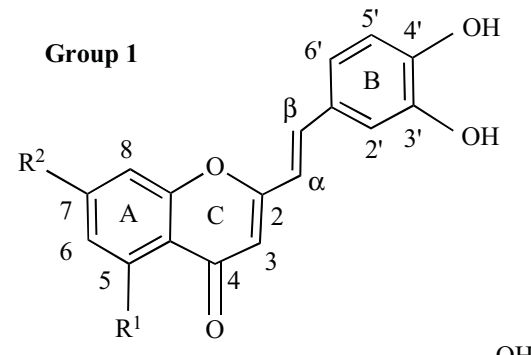

$$
\begin{aligned}
& \text { 1A: } R^{1}=R^{2}=O H \\
& \text { 1B: } R^{1}=H, R^{2}=O H \\
& \text { 1C: } R^{1}=O H, R^{2}=H \\
& \text { 1D: } R^{1}=R^{2}=H
\end{aligned}
$$

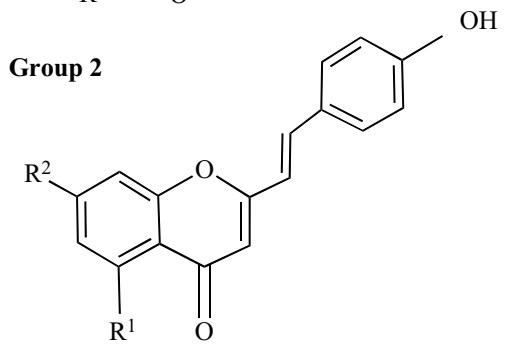

$$
\begin{aligned}
& \text { 2A: } \mathrm{R}^{1}=\mathrm{R}^{2}=\mathrm{OH} \\
& \text { 2B: } \mathrm{R}^{1}=\mathrm{H}, \mathrm{R}^{2}=\mathrm{OH} \\
& \text { 2C: } \mathrm{R}^{1}=\mathrm{OH}, \mathrm{R}^{2}=\mathrm{H} \\
& \text { 2D: } \mathrm{R}^{1}=\mathrm{R}^{2}=\mathrm{H}
\end{aligned}
$$

$$
\begin{aligned}
& \text { 3A: } R^{1}=R^{2}=O H \\
& \text { 3B: } R^{1}=H, R^{2}=O H \\
& \text { 3C: } R^{1}=O H, R^{2}=H \\
& \text { 3D: } R^{1}=R^{2}=H
\end{aligned}
$$

Fig. (1). Chemical structures of the tested 2-SC.

\section{MATERIAL AND METHODS}

\subsection{Reagents}

THP-1 cells, RPMI 1640 medium, penicillinstreptomycin, L-glutamine, fetal bovine serum (FBS), igepal, dithiothreitol, phenylmethanesulfonyl fluoride, aprotinin, leupeptin, pepsatin, and LPS from Escherichia Coli O26:B6 were obtained from Sigma-Aldrich (St Louis, MO). All the reagents used were of analytical grade.

2-Styrylchromones 1A-1D, 2A-2D and 3A-3D were synthesised by the three step Baker-Venkataraman method, starting from the $O$-protected 2'-hydroxyacetophenones and cinnamoyl chlorides [29]. The first step involves the $O$ acylation of the appropriate 2'-hydroxyacetophenones with cinnamoyl chloride derivatives to give 2'-cinnamoyloxyacetophenones. These intermediates were converted into 5-aryl-3-hydroxy-1-(2-hydroxyaryl)-2,4-pentadien-1-ones by the base-catalysed Baker-Venkataraman rearrangement [3032]. The cyclodehydration of these $\beta$-diketones with a mixture of DMSO and a catalytic amount of iodine or $p$ toluenesulfonic acid gives polybenzyloxy-2-SC, which were debenzylated by treatment with hydrogen bromide in acetic acid at reflux, to give the expected hydroxy-2-SC 1A-1D, 2A-2D and 3A-3D, with NMR spectra identical to those in the cited literature.

\subsection{Equipment}

A microplate reader (Synergy HT, BIO-TEK), was used to perform the chemiluminescence and absorbance readings.

\subsection{Cell Culture}

THP-1 cells were maintained in RPMI 1640 medium supplemented with penicillin $(100 \mathrm{U} / \mathrm{mL})$, streptomycin $(100$ $\mu \mathrm{g} / \mathrm{mL})$, L-glutamine $(2 \mathrm{mmol} / \mathrm{L})$ and $10 \% \mathrm{FBS}$ in a $5 \% \mathrm{CO}_{2}$ humid atmosphere at $37^{\circ} \mathrm{C}$.

\subsection{NF-kB Activation}

THP- 1 cells $\left(1 \times 10^{6}\right.$ cells $\left./ \mathrm{mL}\right)$ were cultivated in 6-well plates and incubated with the test compounds or vehicle (DMSO) for $90 \mathrm{~min}$ and subsequently stimulated with LPS $(0.1 \mu \mathrm{g} / \mathrm{mL})$ for $30 \mathrm{~min}$. The nuclear extracts were then obtained according to a previously described method [33] with minor modifications. Cells were collected on ice, centrifuged $(870 \times \mathrm{g})$ at $4^{\circ} \mathrm{C}$, for $5 \mathrm{~min}$, and ressuspended in $1 \mathrm{~mL}$ of cell lysis buffer [10 mM Hepes (pH 7.9), $1.5 \mathrm{mM} \mathrm{MgCl}, 10 \mathrm{mM}$ $\mathrm{KCl}, 0.5 \mathrm{mM}$ EDTA, $0.1 \mathrm{mM}$ EGTA] supplemented with $2 \%$ igepal, $1 \mathrm{mM}$ dithiothreitol and $0.25 \mathrm{mM}$ phenylmethanesulfonyl fluoride. The samples were then incubated on ice for $15 \mathrm{~min}$ and centrifuged $(13,000 \mathrm{x} \mathrm{g})$ at $4^{\circ} \mathrm{C}$, for $5 \mathrm{~min}$. The supernatant was removed and the nuclear pellets were ressuspended in $100 \mu \mathrm{L}$ of nuclear lysis buffer solution [20 mM Hepes (pH 7.9), $420 \mathrm{mM} \mathrm{NaCl}, 1.5 \mathrm{mM}$ $\mathrm{MgCl}_{2}, 0.5 \mathrm{mM}$ EDTA, and $20 \%$ glycerol] supplemented with $1 \mathrm{mM}$ dithiothreitol, $0.25 \mathrm{mM}$ phenylmethanesulfonyl, and $5 \mu \mathrm{g} / \mathrm{mL}$ of each of the following protease inhibitors: aprotinin, leupeptin, and pepsatin. The mixture was kept on ice for $30 \mathrm{~min}$, under intermittent agitation, and further centrifuged $(13,000 \mathrm{x} \mathrm{g})$ at $4^{\circ} \mathrm{C}$, for $10 \mathrm{~min}$. The supernatant was collected and stored at $-80^{\circ} \mathrm{C}$. The protein content was measured using the DC Bio-Rad protein assay kit (Bio-Rad Laboratories, Hercules, California, USA).

The activated NF-kB contained in the nuclear extracts was measured by immunoassay, using a commercially available ELISA kit (Trans AM NF-kB p50 chemi) from Active Motif (Carlsbad, CA), according to the manufacturer's instructions. Briefly, NF-kB was captured by binding to a con- 


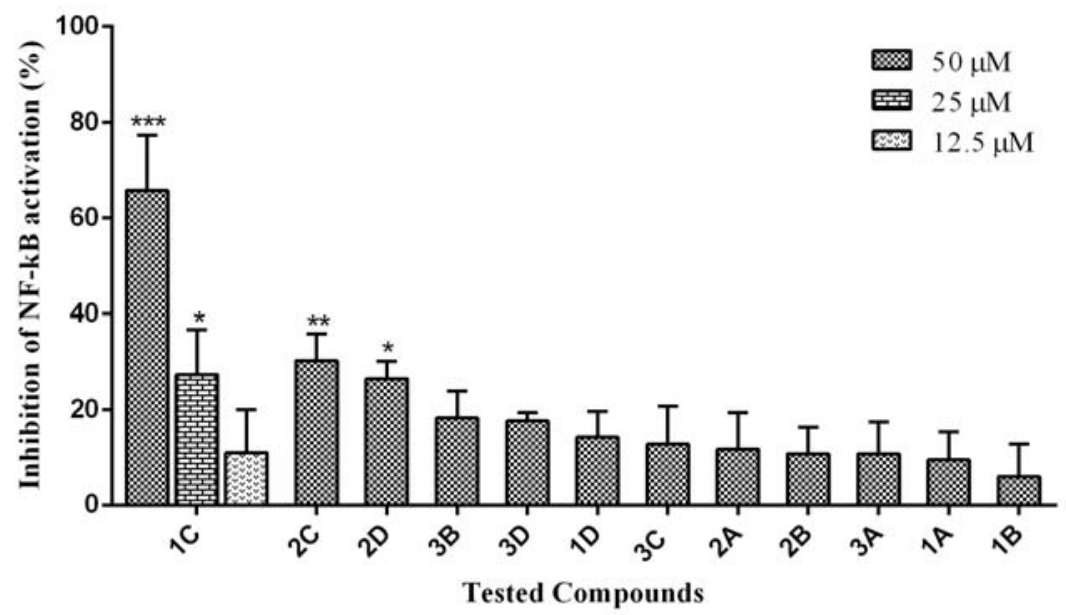

Fig. (2). Inhibition of LPS-induced NF-kB activation in THP-1 cells by 2-SC (1A-1D, 2A-2D, 3A-3D). Each bar represents the percentage of reduction of p-50-dependent chemiluminescence signal relatively to control. The compounds were tested at the concentration of $50 \mu \mathrm{M}$, except where otherwise indicated. The control represents LPS-stimulated cells with DMSO. Each value represents mean \pm SEM of four experiments. ${ }^{*} * * \mathrm{P}<0.001,{ }^{*} * \mathrm{P}<0.01,{ }^{*} \mathrm{P}<0.05$, significantly different from control.

sensus oligonucleotide (5'-GGGACTTTCC-3') immobilized on a 96-well plate. The p50 subunit of NF-kB was determined by a chemiluminescent reaction using a specific primary antibody and a secondary horseradish peroxidaseconjugated antibody. The results were expressed as the reduction of $\mathrm{p} 50$-dependent chemiluminescence signal relatively to control (\%).

\subsection{Cytokines/Chemokine Production}

THP- 1 cells $\left(1 \times 10^{6}\right.$ cells $\left./ \mathrm{mL}\right)$ were cultivated in 6 -well plates and incubated with the test compounds or vehicle (DMSO) for $90 \mathrm{~min}$ and subsequently stimulated with LPS $(0.1 \mu \mathrm{g} / \mathrm{mL})$ for $14 \mathrm{~h}$. The cultures were then collected into microcentrifuge tubes and centrifuged $(1,000 \mathrm{x} \mathrm{g})$ for 10 min. The supernatant was assayed for secreted cytokines (TNF- $\alpha$, IL-1 $\beta$, and IL-6), and chemokine (IL-8) using a commercially available ELISA Kit from SABiosciences (Frederick, MDbe), according to the manufacturer's instructions. The detection was made by reading the absorbance at $450 \mathrm{~nm}$. The results were expressed as the reduction of cytokines/chemokine-dependent absorption at $450 \mathrm{~nm}$ relatively to control $(\%)$.

\subsection{Cytotoxicity}

The effect of the 2-SC on the cell viability was assessed by the lactate dehydrogenase (LDH) leakage (as a measure of cell membrane integrity). The LDH activity was determined by following the rate of oxidation of NADH at 340 $\mathrm{nm}$ [34].

\subsection{Statistical Analysis}

The statistical analysis was performed by one-way analysis of variance (ANOVA) followed by Dunnett's multicomparison test using GraphPad Prism version 5.00 for Windows, GraphPad Software, San Diego California, USA, http:/www.graphpad.com. When comparing with control group, values of $P$ less than 0.05 were considered significant.

\section{RESULTS}

\subsection{NF-kB Activation}

Among the tested 2-SC from group 1, compound $\mathbf{1 C}$ was the most active, inhibiting the NF-kB activation in $65.7 \pm$ $11.5 \%$ for the concentration of $50 \mu \mathrm{M}$. From group 2, compounds 2C and 2D appeared as the most actives, inhibiting the NF-kB activation in $30.2 \pm 5.6 \%$ and $26.5 \pm 3.7 \%$, respectively, for the concentration of $50 \mu \mathrm{M}$. 2-SC from group 3 revealed similar activities. Overall, compounds $\mathbf{1 C}, \mathbf{2 C}$ and 2D were the most potent and were able to significantly reduce the NF-kB activation induced by stimulation with LPS, compound $1 \mathrm{C}$ being the most effective of all. Therefore, this compound was tested at smaller concentrations exhibiting a concentration-dependent effect, which was still significant at $25 \mu \mathrm{M}$ (Fig. 2). The other tested 2-SC rendered an inhibition of NF-kB activation lower than $20 \%$.

\subsection{Cytokines/Chemokine Production}

The three compounds that inhibited NF-kB activation, 1C, 2C and 2D, were tested at the $50 \mu \mathrm{M}$ concentration for their ability to reduce proinflammatory cytokines/chemokine production. All of them were capable of inhibit the production of IL-6 almost totally. Moreover, compound 1C significantly reduced the production of IL-1 $\beta$, TNF- $\alpha$ and IL-8. As well compound 2D was able to significantly reduce the production of IL- $1 \beta$ and TNF- $\alpha$. The 2 -styrylchromone $2 \mathrm{C}$ also inhibited the production of TNF- $\alpha$ in $4.5 \pm 2.0 \%$. Still compounds $2 \mathrm{C}$ and $\mathbf{2 D}$ seem to induce the production of IL8. The 2-SC 2C also appear to induce IL-1 $\beta$ but in a lower extent (Fig. 3).

\subsection{Cytotoxicity}

None of the tested 2-SC, under the concentration of 50 $\mu \mathrm{M}$, was cytotoxic to THP-1 cells after a 90 min incubation period, as verified by the LDH leakage assay. Compounds 1C, 2C, and 2D were also further incubated for $16 \mathrm{~h}$ with the cells showing no cytotoxic effect (data not shown). 


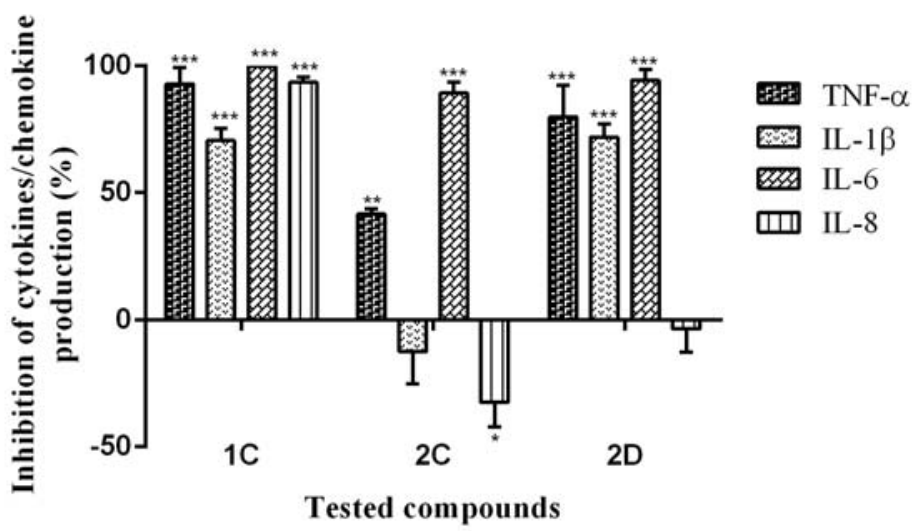

Fig. (3). Inhibition of LPS-induced production of TNF- $\alpha$, IL-1 $\beta$, IL-6, and IL-8 in THP-1 cells by 2-SC (1C, 2C, and 2D). Each bar represents the percentage of reduction of the respective cytokine/chemokine-dependent absorption at $450 \mathrm{~nm}$ relatively to control. The compounds were tested at the concentration of $50 \mu \mathrm{M}$. The control represents LPS-stimulated cells with DMSO. Each value represents mean \pm SEM of three experiments. $* * * \mathrm{P}<0.001, * * \mathrm{P}<0.01, * \mathrm{P}<0.05$, significantly different from control.

\section{DISCUSSION}

Monocytes play an important role in initiating innate immune responses through the secretion of inflammatory mediators, namely cytokines [35].

In the present study we used the THP-1 cells because of their human origin and ability to perform many of the functions of peripheral blood monocytes. Based on similar results of THP-1 and blood monocytes, the use of THP-1 cells allows more reproducibility and the low variation makes them very useful for standardizing test and comparisons between compounds to be feasible [36]. In addition, THP-1 have been previously used to study the inflammatory process $[4,25-$ 28]. Inflammation is the process developed by the innate immunity in response to physical, physiological and/or oxidative stress and is associated with activation of the NF-kB signaling pathway, which is conserved in all multicellular animals [1]. Furthermore, NF-kB is increasingly recognized as a crucial player in many steps of cancer initiation and progression [1]. The involvement of NF-kB proteins in the development of common autoimmune and chronic inflammatory diseases, including rheumatoid arthritis, multiple sclerosis, type 1 diabetes mellitus, thyroid autoimmune diseases, systemic lupus erythematosus as well as inflammatory bowel disease and psoriasis, has been demonstrated by in vitro and in vivo data [37].

Moreover, accepted therapeutic options such as glucocorticoids, cyclosporine, tacrolimus, non-steroidal antiinflammatory drugs (NSAIDs), and sulfasalazine were shown to modulate the NF-kB pathway by several mechanisms. In addition, novel therapeutic strategies that specifically inhibit key elements of this pathway are being developed, showing some interesting results in animal models of the above mentioned diseases, reviewed in [38]. Oxidative stress is defined as an imbalance between production of free radicals and reactive metabolites, so-called oxidants or reactive oxygen species (ROS), and their elimination by protective mechanisms, referred to as antioxidants. This imbalance leads to damage of important biomolecules and cells, with potential impact on the whole organism [39]. Some of the studied compounds had previously shown high scavenging activity against ROS and reactive nitrogen species (RNS)
[21]. Redox status has also been shown to have an impact on NF-kB regulation $[39,40]$. The mechanism for activation of NF-kB by ROS is not clear, and the relationship between NF-kB and ROS is complex. Numerous polyphenols have been shown ascribe to inhibit NF-kB in different cell types. For example, quercetin suppresses NF-kB in J774 cells [41]. Apigenin blocks LPS stimulation of the NF-kB pathway in macrophages [42]. Catechin inhibits phorbol-12-myristate13-acetate (PMA)-induced NF-kB activation at multiple steps in Jurkat T cells [43]. Acacetin inhibits the NF-kB activation in DU145 prostate cancer cells [44]. Luteolin prevents LPS-induced TNF- $\alpha$ expression in cardiac myocytes through the inhibition of the NF-kB signaling pathway [45]. Chrysin suppresses LPS-stimulated proinflammatory responses by blocking NF-kB in microglia cells [46]. Naringenin inhibits NF-kB activity in inflammatory pulmonary diseases induced by human neutrophil elastase [47]. However, the modulation of NF-kB activation by hydroxylated 2$\mathrm{SC}$ was reported here for the first time.

The mechanisms of NF-kB activation are complex and depend on the activator and on the cell type. Herein we focused on the LPS-induced NF-kB activation in phagocytic cells, namely monocytes. LPS, the major outer membrane component present in gram-negative bacteria, consist of a lipid core and polysaccharide side chain joined by a covalent bond. LPS act as the prototypical endotoxin to promote the secretion of proinflammatory cytokines in many cell types. LPS is recognized by TLR4, a member of the TLR family. TLRs are evolutionarily conserved pattern recognition receptors that recognize unique, essential molecules characteristic of various classes of microbes. The function of TLRs as arbitrators of self / nonself discrimination highlights their central role in innate immunity as well as in the initiation of the adaptive immune response [48, 49].

Upon binding of LPS to TLR4, the cytoplasmic region of the receptor recruits MyD88 (myeloid differentiation primary response gene 88), which links TLR4 to IL-1 receptorassociated kinase (IRAK) and TNF receptor-associated factor-6 (TRAF6) that mediates NF-kB activation. On the other hand, the activation of Rac1 and the subsequent production of ROS are key steps involved in NF-kB activation and TNF 
secretion in macrophages activated with LPS. LPS-induced ROS generation and NF-kB activation was shown to be mediated by direct interaction of TLR4 with NADPH oxidase 4 (Nox4), a protein related to the NADPH oxidase 2 (Nox2) present in phagocytic cells, although another Nox enzyme might be involved [40].

While the mechanism of NF-kB inhibition has been considered by some to be related to the antioxidant properties of the compounds $[50,51]$, the relevance of these properties to the activity of flavonoids was questioned by Comalada and coleagues [52] based on the observation that a good antioxidant like kaempferol was a worse NF-kB inhibitor than apigenin, which is a poor antioxidant. A similar situation occurred with 2-SC, i.e., compounds like 1A and 1B, which previously showed high ROS scavenging activity [21], could not inhibit the LPS-induced NF-kB DNA-binding, while compounds 2C and 2D, which are much less active scavengers, were effective in the present study. However, the lack of NF-kB inhibitory activity of good ROS scavengers such as $\mathbf{1 A}$ and $\mathbf{1 B}$ might be related to their poorer hydrophobicity, compared with the active compounds 1C, 2C and 2D, which can difficult their entry into cells. This rational comes in line with the results from a previous study [20], in which compounds 1A-1D were tested for their inhibitory effect on $\mathrm{Cu}^{2+}$-induced oxidation of isolated human serum low density lipoproteins (LDL), an in vitro model of lipid peroxidation. In that work, compounds $1 \mathrm{C}$ and $\mathbf{1 D}$ were much more effective than 1A and 1B. The unexpected differences observed in the antioxidant effectiveness were suggested to be due to the different partitioning of 2-SC into LDL as a function of the number of hydroxyl groups in the molecule. The authors studied the interaction of the SCs with the LDL by absorption and fluorescence spectroscopies and concluded that the less substituted ones interacted with the LDL in more than one site, enhancing their activity. Moreover, Brennan and Oneill [53] exposed the hypothesis that the reactive oxygen model of NF-kB activation depends on the type of cells under study. In their study they reported different susceptibility of Jurkat, EL4 and KB cells to the antioxidant Nacetylcystein, which also did not inhibit TNF-activated NF$\mathrm{kB}$ in $\mathrm{KB}$ cells.

It is important to note that none of the tested 2-SC under the concentration of $50 \mu \mathrm{M}$ was cytotoxic to THP-1 cells as it was seen by LDH leakage assay. LDH is a cytosolic enzyme that is released when the plasma membrane is damaged [54].

The transcription factor NF-kB is responsible for the regulation of genes encoding proinflammatory cytokines [e.g., TNF-a, IL-1, IL-2, IL-6, IL-12, lymphotoxin (LT)a, $\mathrm{LTb}$ and granulocyte macrophage colony-stimulating factor (GM-CSF)], chemokines [e.g., IL-8, macrophage inflammatory protein (MIP)-1a, monocyte chemoattractant protein (MCP)-1, regulated on activation, normal $\mathrm{T}$ Cell expressed and secreted (RANTES) and eotaxin], adhesion molecules [e.g., intercellular adhesion molecule (ICAM), vascular cell adhesion molecule (VCAM) and E-selectin], growth factors and inducible enzymes such as COX-2 and inducible nitric oxide synthase (iNOS) [55]. We focus our study in the effect of 2-SC in proinflammatory cytokines TNF- $\alpha$, IL-1 $\beta$, and IL6 and the chemokine IL- 8 since they are known to be impli- cated in chronic inflammatory and autoimmune diseases such as rheumatoid arthritis, multiple sclerosis, and inflammatory bowel disease [5-8]. Furthermore, the clinical efficacy of drugs that target TNF- $\alpha$, IL-1 $\beta$, and IL-6 (e.g. monoclonal antibodies, receptor antagonists) has been well demonstrated in rheumatoid arthritis and Crohn's disease [5, 5658]. The results obtained in this work show that $\mathbf{1 C}$ is capable of reducing the production of TNF- $\alpha$, IL- $1 \beta$, IL- 6 , and IL-8, most likely by the previous inhibition of NF-kB activation. 2D, however, was unable to reduce IL-8 production. The same happened with $\mathbf{2 C}$, which could not reduce IL-1 $\beta$ production as well. The fact that these two compounds were less potent inhibitors of NF-kB activation than $\mathbf{1 C}$ may be an explanation for the different results.

In this study, new inhibitors of NF-kB activity were found. From all the tested compounds, 1C showed the highest activity in inhibiting this transcription factor and was also the best in reducing the production of all proinflammatory cytokines/chemokine tested. Thus, compound $\mathbf{1 C}$ is a promising scaffold for the development of new anti-inflammatory drugs.

\section{CONFLICT OF INTEREST}

The authors confirm that this article content has no conflict of interest.

\section{ACKNOWLEDGEMENTS}

The authors acknowledge Fundação para a Ciência e Tecnologia (FCT) and FEDER financial support for the project POCI/QUI/59284/2004 and the Organic Chemistry Research Unit ( $\mathrm{n}^{\circ}$ 62; Univ. Aveiro). Marisa Freitas, Daniela Ribeiro and Ana Gomes acknowledges FCT the financial support for the Pos-doc grant (SFRH/BPD/76909/2011), and for the PhD grants (SFRH/BD/72966/2010 and $\mathrm{SFRH} / \mathrm{BD} / 23299 / 2005$, respectively) in the ambit of "POPH - QREN - Tipologia 4.1 - Formação Avançada" cosponsored by FSE and national funds of MCTES.

\section{REFERENCES}

[1] Hoesel, B.; Schmid, J.A. The complexity of NF-kappa B signaling in inflammation and cancer. Mol. Cancer, 2013, 12(86), 1-15.

[2] Bours, V.; Bonizzi, G.; Bentires-Alj, M.; Bureau, F.; Piette, J.; Lekeux, P.; Merville, M.P. NF-kappa B activation in response to toxical and therapeutical agents: role in inflammation and cancer treatment. Toxicology, 2000, 153(1-3), 27-38.

[3] Palsson-McDermott, E.M.; O'Neill, L.A.J. Signal transduction by the lipopolysaccharide receptor, Toll-like receptor-4. Immunology, 2004, 113(2), 153-162.

[4] Aikawa, Y.; Yamamoto, M.; Yamamoto, T.; Morimoto, K.; Tanaka, K. An anti-rheumatic agent T-614 inhibits NF-kappa B activation in LPS- and TNF-alpha-stimulated THP-1 cells without interfering with 1 kappa B alpha degradation. Inflamm. Res., 2002, 51(4), 188-194.

[5] Burger, D.; Dayer, J.M.; Palmer, G.; Gabay, C. Is IL-1 a good therapeutic target in the treatment of arthritis? Best Pract. Res. Clin. Rheumatol., 2006, 20(5), 879-896.

[6] Feldmann, M.; Brennan, F.M.; Maini, R.N. Role of cytokines in rheumatoid arthritis. Annu. Rev. Immunol., 1996, 14, 397-440.

[7] Kollias, G.; Douni, E.; Kassiotis, G.; Kontoyiannis, D. The function of tumour necrosis factor and receptors in models of multi-organ inflammation, rheumatoid arthritis, multiple sclerosis and inflammatory bowel disease. Ann. Rheum. Dis., 1999, 58, 3239. 
[8] Ishihara, K.; Hirano, T. IL-6 in autoimmune disease and chronic inflammatory proliferative disease. Cytokine Growth Factor Rev., 2002, 13(4-5), 357-368.

[9] Yang, L.; Qiao, L.R.; Xie, D.; Yuan, Y.H.; Chen, N.H.; Dai, J.G.; Guo, S.X. 2-(2-Phenylethyl)chromones from Chinese eaglewood. Phytochemistry, 2012, 76, 92-97.

[10] Gerwick, W.H. 6-Desmethoxyhormothamnione, a new cytotoxic styrylchromone from the marine cryptophyte Chrysophaeum taylori. J. Nat. Prod., 1989, 52(2), 252-256.

[11] Gerwick, W.H.; Lopez, A.; Vanduyne, G.D.; Clardy, J.; Ortiz, W.; Baez, A. Hormothamnione, a novel cytotoxic styrylchromone from the Marine Cyanophyte Hormothamnion-Enteromorphoides Grunow. Tetrahedron Lett., 1986, 27(18), 1979-1982.

[12] Momoi, K.; Sugita, Y.; Ishihara, M.; Satoh, K.; Kikuchi, H.; Hashimoto, K.; Yokoe, I.; Nishikawa, H.; Fujisawa, S.; Sakagami, H. Cytotoxic activity of styrylchromones against human tumor cell lines. In Vivo, 2005, 19(1), 157-163.

[13] Shaw, A.Y.; Chang, C.Y.; Liau, H.H.; Lu, P.J.; Chen, H.L.; Yang, C.N.; Li, H.Y. Synthesis of 2-styrylchromones as a novel class of antiproliferative agents targeting carcinoma cells. Eur. J. Med. Chem., 2009, 44(6), 2552-2562.

[14] Doria, G.; Romeo, C.; Forgione, A.; Sberze, P.; Tibolla, N.; Corno, M.L.; Cruzzola, G.; Cadelli, G. Anti-allergic agents .3. Substituted trans-2-ethenyl-4 oxo-4h-1-benzopyran-6-carboxylic acids. Eur. J. Med. Chem., 1979, 14(4), 347-351.

[15] Conti, C.; Mastromarino, P.; Goldoni, P.; Portalone, G.; Desideri, N. Synthesis and anti-rhinovirus properties of fluoro-substituted flavonoids. Antivir. Chem. Chemother., 2005, 16(4), 267-276.

[16] Desideri, N.; Conti, C.; Mastromarino, P.; Mastropaolo, F. Synthesis and anti-rhinovirus activity of 2-styrylchromones. Antivir. Chem. Chemother., 2000, 11(6), 373-381.

[17] Rocha-Pereira, J.; Cunha, R.; Pinto, D.C.G.A.; Silva, A.M.S.; Nascimento, M.S. (E)-2-Styrylchromones as potential antinorovirus agents. Bioorgan. Med. Chem., 2010, 18(12), 4195-4201.

[18] Fernandes, E.; Carvalho, F.; Silva, A.M.S.; Santos, C.M.M.; Pinto, D.C.G.A.; Cavaleiro, J.A.S.; Bastos, M.D. 2-styrylchromones as novel inhibitors of xanthine oxidase. A structure-activity study. $J$. Enzym. Inhib. Med. Ch., 2002, 17(1), 45-48.

[19] Fernandes, E.; Carvalho, M.; Carvalho, F.; Silva, A.M.S.; Santos, C.M.M.; Pinto, D.C.G.A.; Cavaleiro, J.A.S.; Bastos, M.D. Hepatoprotective activity of polyhydroxylated 2-styrylchromones against tert-butylhydroperoxide induced toxicity in freshly isolated rat hepatocytes. Arch. Toxicol., 2003, 77(9), 500-505.

[20] Filipe, P.; Silva, A.M.S.; Morliere, P.; Brito, C.M.; Patterson, L.K.; Hug, G.L.; Silva, J.N.; Cavaleiro, J.A.S.; Maziere, J.C.; Freitas, J.P.; Santus, R. Polyhydroxylated 2-styrylchromones as potent antioxidants. Biochem. Pharmacol., 2004, 67(12), 2207-2218.

[21] Gomes, A.; Fernandes, E.; Silva, A.M.S.; Santos, C.M.M.; Pinto, D.C.G.A.; Cavaleiro, J.A.S.; Lima, J.L.F.C. 2-Styrylchromones: Novel strong scavengers of reactive oxygen and nitrogen species. Bioorgan. Med. Chem., 2007, 15(18), 6027-6036.

[22] Gomes, A.; Fernandes, E.; Silva, A.M.S.; Pinto, D.C.G.A.; Santos, C.M.M.; Cavaleiro, J.A.S.; Lima, J.L.F.C. Anti-inflammatory potential of 2-styrylchromones regarding their interference with arachidonic acid metabolic pathways. Biochem. Pharmacol., 2009, 78(2), 171-177.

[23] Kim, J.S.; Jobin, C. The flavonoid luteolin prevents lipopolysaccharide-induced NF-kappa B signalling and gene expression by blocking I kappa B kinase activity in intestinal epithelial cells and bone-marrow derived dendritic cells. Immunology, 2005, 115(3), 375-387.

[24] Gomes, A.; Fernandes, E.; Lima, J.L.F.C.; Mira, L.; Corvo, M.L. Molecular mechanisms of anti-inflammatory activity mediated by flavonoids. Curr. Med. Chem., 2008, 15(16), 1586-1605.

[25] Zhao, Y.; Joshi-Barve, S.; Barve, S.; Chen, L.H. Eicosapentaenoic acid prevents LPS-induced TNF-alpha expression by preventing NF-kappa B activation. J. Am. Coll. Nutr., 2004, 23(1), 71-78.

[26] Yeh, C.C.; Kao, S.J.; Lin, C.C.; Wang, S.D.; Liu, C.J.; Kao, S.T. The immunomodulation of endotoxin-induced acute lung injury by hesperidin in vivo and in vitro. Life Sci., 2007, 80(20), 1821-1831.

[27] Lee, E.H.; Rikihisa, Y. Absence of tumor necrosis factor alpha, interleukin-6 (IL-6), and granulocyte-macrophage colonystimulating factor expression but presence of IL-1 beta, IL-8, and IL-10 expression in human monocytes exposed to viable or killed Ehrlichia chaffeensis. Infect. Immun., 1996, 64(10), 4211-4219.
[28] Berg, J.; Fellier, H.; Christoph, T.; Grarup, J.; Stimmeder, D. The analgesic NSAID lornoxicam inhibits cyclooxygenase (COX)-1/-2, inducible nitric oxide synthase (iNOS), and the formation of interleukin (IL)-6 in vitro. Inflamm. Res., 1999, 48(7), 369-379.

[29] Santos, C.M.M.; Silva, A.M.S.; Cavaleiro, J.A.S. Synthesis of new hydroxy-2-styrylchromones. Eur. J. Org. Chem., 2003, 23, 45754585.

[30] Baker, W. Molecular rearrangement of some oacyloxyacetophenones and the mechanism of the production of 3acylchromones. J. Chem. Soc., 1933, 1381-1389.

[31] Mahal, H.S.; Venkataraman, K. Synthetical experiments in the chromone group Part XIV The action of sodamide on 1-acyloxy-2acetonaphthones. J. Chem. Soc., 1934, 1767-1769.

[32] Price, W.A.; Silva, A.M.S.; Cavaleiro, J.A.S. 2-Styrylchromones Biological Action, Synthesis and Reactivity. Heterocycles, 1993, 36(11), 2601-2612.

[33] Freitas, M.; Fernandes, E. Zinc, cadmium and nickel increase the activation of NF-kappa B and the release of cytokines from THP-1 monocytic cells. Metallomics, 2011, 3(11), 1238-1243.

[34] Capela, J.P.; Ruscher, K.; Lautenschlager, M.; Freyer, D.; Dirnagl, U.; Gaio, A.R.; Bastos, M.L.; Meisel, A.; Carvalho, F. Ecstasyinduced cell death in cortical neuronal cultures is serotonin $2 \mathrm{~A}$ receptor-dependent and potentiated under hyperthermia. Neuroscience, 2006, 139(3), 1069-1081.

[35] Spahn, J.H.; Kreisel, D. Monocytes in sterile inflammation: recruitment and functional consequences. Arch. Immunol. Ther. Exp. (Warsz), 2014, 62(3), 187-194.

[36] Heil, T.L.; Volkmann, K.R.; Wataha, J.C.; Lockwood, P.E. Human peripheral blood monocytes versus THP-1 monocytes for in vitro biocompatibility testing of dental material components. J. Oral. Rehabil., 2002, 29(5), 401-407.

[37] Tripathi, P.; Aggarwal, A. NF-kB transcription factor: a key player in the generation of immune response. Curr. Sci. India, 2006, 90(4), 519-531.

[38] Kurylowicz, A.; Nauman, J. The role of nuclear factor-kappa B in the development of autoimmune diseases: a link between genes and environment. Acta Biochim. Pol., 2008, 55(4), 629-647.

[39] Reuter, S.; Gupta, S.C.; Chaturvedi, M.M.; Aggarwal, B.B. Oxidative stress, inflammation, and cancer: how are they linked? Free Radic. Biol. Med., 2010, $49(11), 1603-1616$.

[40] Gloire, G.; Legrand-Poels, S.; Piette, J. NF-kappa B activation by reactive oxygen species: Fifteen years later. Biochem. Pharmacol., 2006, 72(11), 1493-1505.

[41] Hamalainen, M.; Nieminen, R.; Vuorela, P.; Heinonen, M.; Moilanen, E. Anti-inflammatory effects of flavonoids: genistein, kaempferol, quercetin, and daidzein inhibit STAT-1 and NF-kappa $\mathrm{B}$ activations, whereas flavone, isorhamnetin, naringenin, and pelargonidin inhibit only NF-kappa B activation along with their inhibitory effect on iNOS expression and NO production in activated macrophages. Mediat. Inflamm., 2007, 2007, 1-10.

[42] Nicholas, C.; Batra, S.; Vargo, M.A.; Voss, O.H.; Gavrilin, M.A.; Wewers, M.D.; Guttridge, D.C.; Grotewold, E.; Doseff, A.I. Apigenin blocks lipopolysaccharide-induced lethality in vivo and proinflammatory cytokines expression by inactivating NF-kappa B through the suppression of p65 phosphorylation. J. Immunol., 2007, 179(10), 7121-7127.

[43] Mackenzie, G.G.; Carrasquedo, F.; Delfino, J.M.; Keen, C.L.; Fraga, C.G.; Oteiza, P.I. Epicatechin, catechin, and dimeric procyanidins inhibit PMA-induced NF-kappaB activation at multiple steps in Jurkat T cells. FASEB J., 2004, 18(1), 167-169.

[44] Shen, K.H.; Hung, S.H.; Yin, L.T.; Huang, C.S.; Chao, C.H.; Liu, C.L.; Shih, Y.W. Acacetin, a flavonoid, inhibits the invasion and migration of human prostate cancer DU145 cells via inactivation of the p38 MAPK signaling pathway. Mol. Cell. Biochem., 2010, 333(1-2), 279-291.

[45] Lv, L.H.; Lv, L.H.; Zhang, Y.B.; Kong, Q.H. Luteolin Prevents LPS-Induced TNF-alpha Expression in Cardiac Myocytes Through Inhibiting NF-kappa B Signaling Pathway. Inflammation, 2011, 34(6), 620-629.

[46] Ha, S.K.; Moon, E.; Kim, S.Y. Chrysin suppresses LPS-stimulated proinflammatory responses by blocking NF-kappa B and JNK activations in microglia cells. Neurosci. Lett., 2010, 485(3), 143147.

[47] Yang, J.; Li, Q.; Zhou, X.D.; Kolosov, V.P.; Perelman, J.M. Naringenin attenuates mucous hypersecretion by modulating reactive oxygen species production and inhibiting NF-kappa B 
activity via EGFR-PI3K-Akt/ERK MAPKinase signaling in human airway epithelial cells. Mol. Cell. Biochem., 2011, 351(1-2), 29-40.

[48] Yang, L.Y.; Francois, F.; Pei, Z.H. Molecular Pathways: Pathogenesis and Clinical Implications of Microbiome Alteration in Esophagitis and Barrett Esophagus. Clin. Cancer Res., 2012, 18(8), 2138-2144.

[49] Sen, R.; Smale, S.T. Selectivity of the NF-kappa B Response. Csh Perspect. Biol., 2010, 2(4), 1-15.

[50] Asehnoune, K.; Strassheim, D.; Mitra, S.; Kim, J.Y.; Abraham, E. Involvement of reactive oxygen species in Toll-like receptor 4dependent activation of NF-kappa B. J. Immunol., 2004, 172(4), 2522-2529.

[51] Ryan, K.A.; Smith, M.F.; Sanders, M.K.; Ernst, P.B. Reactive oxygen and nitrogen species differentially regulate toll-like receptor 4-mediated activation of NF-kappa B and interleukin-8 expression. Infect. Immun., 2004, 72(4), 2123-2130.

[52] Comalada, M.; Ballester, I.; Bailon, E.; Sierra, S.; Xaus, J.; Galvez, J.; de Medina, F.S.; Zarzuelo, A. Inhibition of pro-inflammatory markers in primary bone marrow-derived mouse macrophages by naturally occurring flavonoids: analysis of the structure-activity relationship. Biochem. Pharmacol., 2006, 72(8), 1010-1021.

[53] Brennan, P.; Oneill, L.A.J. Effects of Oxidants and Antioxidants on Nuclear Factor Kappa-B Activation in 3 Different Cell-Lines Evidence against a Universal Hypothesis Involving Oxygen Radicals. Bba-Gene Struct. Expr., 1995, 1260(2), 167-175.

[54] Chan, F.K.; Moriwaki, K.; De Rosa, M.J. Detection of necrosis by release of lactate dehydrogenase activity. Methods Mol. Biol., 2013, 979, 65-70.

[55] Valko, M.; Morris, H.; Cronin, M.T.D. Metals, toxicity and oxidative stress. Curr. Med. Chem., 2005, 12(10), 1161-1208.

[56] Feldmann, M.; Maini, R.N. TNF defined as a therapeutic target for rheumatoid arthritis and other autoimmune diseases. Nat. Med., 2003, $9(10), 1245-1250$.

[57] Rutgeerts, P.; Van Assche, G.; Vermeire, S. Optimizing anti-TNF treatment in inflammatory bowel disease. Gastroenterology, 2004, 126(6), 1593-1610.

[58] Mima, T.; Nishimoto, N. Current Opinion in Rheumatology. Curr. Opin. Rheumatol., 2009, 21(3), 224-230. 